\title{
Düşünce Kontrol Yeteneği Ölçeğinin Türkçe Versiyonu: Bir Ölçek Uyarlama Çalışması*
}

\author{
Turkish Version of the Thought Control Capability \\ Questionnaire: A Scale Adaptation Study
}

\begin{abstract}
Hakan SARIÇAM**, Abdullah MERT***
Öz: Bu çalışmanın amacı Düşünce Kontrol Yeteneği Ölçeği'nin (DKYÖ-25 ve DKYÖ-8) Türk külttürüne uyarlamak ve ölçeğin psikometrik özelliklerini incelemektir. Araştırma, üç farklı çalışma grubunda yer alan ve yaşları 18 ile 44 arasında değişen toplam $656(204+255+201)$ yetişkin katılımcıdan oluşmaktadır. İlk çalışmada, açımlayıcı faktör analizi sonuçlarına göre 25 maddelik DKYÖ'nün orijinalinde olduğu gibi Türkçe formunun da tek boyuta sahip olduğu ve toplam varyansın \%42.49'unu açıkladığı görülmüştür. Yapılan DFA sonucu ölçeğin uyum iyiliği değerleri $\chi^{2} / \mathrm{sd}=2.91$, RMSEA = .066, CFI= .92, GFI= .93, IFI= $.93, \mathrm{NFI}=.93, \mathrm{RFI}=.94$ ve SRMR $=.042$ şeklinde hesaplanmıştır. Madde faktör yükleri ise .31 ile .69 arasında sıralanmaktadır. Eşdeğer ölçek (ölçüt) geçerliği çalışmasında DKYÖ-25 ile Tekrarlayıcı Düşünme Ölçeği arasında $\mathrm{p}<.01$ önem düzeyinde $r=-.62$, DKYÖ ile Bilişsel esneklik (alternatifler) ve Bilişsel esneklik (kontrol) arasında $\mathrm{p}<.01$ önem düzeyinde sırasıyla $r=.53 ; .65$ pozitif ilişkiler bulunmuştur. Ölçeğin iç tutarlık katsayısı .93 olarak tespit edilmiştir. Düzeltilmiş madde toplam korelasyon katsayıları .37 ile .70 arasında hesaplanmıştır. İkinci çalışmada, AFA'ya göre 8 maddelik DKYÖ'nün tek boyutlu olduğu ve bu tek boyutu ölçeğin toplam varyansın \%55'ini açıkladığı tespit edilmiştir. Ölçeğin doğrulayıcı faktör analizine göre ölçeğin uyum iyiliği değerleri $\chi^{2} / \mathrm{sd}=1.98, \mathrm{CFI}=.97$, $\mathrm{GFI}=.93, \mathrm{IFI}=.97, \mathrm{NFI}=.95, \mathrm{RFI}=.93$ ve $\mathrm{SRMR}=.048$ şeklinde bulunmuştur. Ayrica madde faktör yükleri .58 ile .77 arasında değişmektedir. Ölçeğin iç tutarlık katsayısı .88 şeklinde hesaplanmıştır. Düzeltilmiş madde toplam korelasyon katsayıları .56 ile .71 arasında değişmektedir. Tüm bu sonuçlar, Düşünce Kontrol Yeteneği Ölçeği'nin Uzun ve Kısa sürümünün Türk yetişkinlerde kullanılabilecek geçerli ve güvenilir bir ölçme aracı olduğunu göstermiş̧tir.
\end{abstract}

Anahtar Kelimeler: Düşünce kontrol, geçerlik, güvenirlik

\begin{abstract}
The purpose of this study is to adapt The Thought Control Ability Questionnaire (DKYÖ-25 and DKYÖ-8) to Turkish culture and to evaluate the psychometric properties of the questionnaire. The study consists of a total of 656 adult participants $(204+255+201)$ aged between 18 and 44 in three different study groups. In the first study, it was observed that the Turkish form of the 25 -item Thought Control Ability Questionnaire (TCAQ), as in the original, had only one dimension explaining $42.49 \%$ of the total variance according to the results of exploratory factor analysis. According to the confirmatory factor analysis result, the goodness fit values of the scale are $\chi^{2} / \mathrm{sd}=2.91$, RMSEA $=.066$, CFI $=.92$, GFI $=$ $.93, \mathrm{IFI}=.93, \mathrm{NFI}=.93, \mathrm{RFI}=.94$ ve $\mathrm{SRMR}=.042$. Item factor loads are ranked between .31 and $.69 . \mathrm{In}$ the study of equivalent scale (criterion) validity, between the Thought Control Ability Questionnaire (TCAQ-25) and the Repetitive Thinking Scale, $\mathrm{p}<.01$ severity level of $\mathrm{r}=-.62$ and between Thought Control Ability Questionnaire (TCAQ) and cognitive flexibility (alternatives) and cognitive flexibility (control) at the $\mathrm{p}<.01$ severity level, respectively, $\mathrm{r}=.53$ and $\mathrm{r}=.65$ positive relationships have been found. The internal consistency coefficient of the scale was determined as .93. The total correlation coefficients of the corrected items were calculated between .37 and .70. In the second study, according to exploratory factor analysis (EFA), it was found that the 8-item Thought Control Ability Questionnaire (TCAQ) was one-dimensional and this one-dimensional explained 55\% of the total variance of the scale. According to
\end{abstract}

\footnotetext{
* Bu çalışmanın bir kısmı 12-14 Mayıs 2017 tarihlerinde İstanbul'da gerçekleştirilen 2. Avrasya Pozitif Psikoloji Kongresinde sözlü bildiri olarak sunulmuştur.

** Doç. Dr., Sivas Cumhuriyet Üniversitesi, Eğitim Fakültesi, Sivas-Türkiye, ORCID:0000-0002-8723-1199, eposta: hakansaricam@gmail.com

*** Dr. Öğretim Üyesi, Uşak Üniversitesi, Eğitim Fakültesi, Uşak-Türkiye, ORCID: 0000-0003-0653-2297, e-posta: abdullahmert@gmail.com
} 
confirmatory factor analysis, the goodness fit values of the scale were found as $\chi 2 / \mathrm{sd}=1.98, \mathrm{CFI}=.97$, $\mathrm{GFI}=.93, \mathrm{IFI}=.97, \mathrm{NFI}=.95, \mathrm{RFI}=.93$ and $\mathrm{SRMR}=0.48$. Also, the item factor loads range from .58 to .77. The internal reliability coefficient of the scale was calculated as .88 . The total correlation coefficients of the adjusted items range from .56 to .71 . All these results proved that both the long and short version of the Thought Control Ability Questionnaire was a valid and reliable measurement tool that could be used in Turkish adults.

Keywords: Thought control, validity, reliability

\section{Giriş}

Aklın; duyum, algı, izlenim ve tasarımlardan ayrı bir biçimde bağımsız ve özgün durumu, düşünme olarak tanımlanır (Türk Dil Kurumu, [TDK], 2019). Düşünme, bireyde var olan bilgi ve deneyimler sayesinde gerçekleşen mantığ1 içeren zihinsel bir süreçtir (Başerer, 2017; Presseisen, 1991). Düşünme, zihinde doğal olarak ortaya çıtığından çoğu insan düşünmeyi sıradan basit bir durum olarak algılayarak sistematik düşünme üzerinde pek kafa yormadan zihnini yormaktan kaçınır (Başerer ve Duman, 2018; Güneş, 2012). Bu durumda düşünce kontrolü kavramı kendini gösterir. Düşünce kontrol yeteneği (DKY), bireylerin istenmeyen ve zorlayıc1/davetsiz düşünceleri akıldan çıkarmaları için kullandıkları ve kontrol mekanizmasını bireyin kendi yönettiği bir düşünme tarzıdır (Martin ve Tesser, 1996; Wells ve Davies, 1994). Kısacası DKY belirli düşünceleri düşünmemeye çalışmaktır (Wells ve Davies, 1994). Freud'un savunma mekanizmalarının ön koşulu olan "bastırmadan (düşünceleri)" farklı olarak DKY yıkıcı, zararlı düşünceleri ortadan kaldırır ve yaratıcı aktivitelere odaklanmayı sağlar. Ayrıca bastırma bir müddet sonra otomatikleşebilir fakat DKY bilinçlidir. Wegner, Schneider, Carter ve White'a (1987) göre düşünce kontrol yeteneği, zorlayıc1/davetsiz düşünceleri durdurmak için bilinçli, çaba dolu bir işlem sürecidir. $\mathrm{Bu}$ süreç sonucunda bilişsel kaynaklara ulaşım sağlanmalıdır. İkinci aşama ise yeni düşünce örneklerini gösteren otomatik izleme sürecidir. Otomatik izleme süreci hedef yönelimli düşünceyi aktif ederek bireyin toparlanmasını sağlar. $\mathrm{Bu}$ bağlamda düşünce kontrol yeteneği, öz-düzenleme kapasitesi içinde yer almakta olup; davranış ve düşüncelerin hedef yönelimli kontrolüdür. İleri düzeyde düşünce kontrolü, yüksek çalışan bellek kapasitesi ve akışkan zekâyla ilgilidir (Brewin ve Beaton, 2002).

Alanyazında DKY ile karıştırılan bilişsel farkındalık ve üst biliş (meta biliş) gibi kavramlar bulunmaktadır. Bir düşünme sistematiği olan bilişsel farkındalık, öğrenmeyi öğrenebilme, öğrenme sürecini değerlendirebilme ve bu sürece dair gerekli düzenleme işlemini yapabilme, zihnin dili, kişinin kendi bilişleri hakkındaki farkındalığı olarak tanımlanabilir (Sarıçam, 2018; Sarıçam ve Çelik, 2018). 1979'da Flavell tarafından literatüre kazandırılan üst biliş ise, bilişleri kontrol eden üst düzey bir düşünme biçimidir (Kacar ve Sarıçam, 2015). Birey ne düşündüğünün ve ne bildiğinin farkındadır ve bilişsel süreçlerini kontrol edebilmektedir (Tosun ve Irak, 2008). Üst biliş bireyin kendini anlaması, yönlendirme ve kontrol edebilmesidir (Garner ve Alexander, 1989; Reeve ve Brown, 1985). Öte taraftan bu üst bilişsel beceri bazen ruminatif düşünceler veya işlevsel olmayan düşünceler gibi olumsuz bir hal alabilmekte ve ruh sağlığı açısından negatif bir etkiye sebep olabilmektedir (Kaçar ve Sarıçam, 2015; Tosun ve Irak, 2008).

Birey yaşantısı boyunca birçok negatif bilişlerle karşılaşır ve bunlardan kurtulabilmek için çeşitli düşünce kontrol stratejileri geliştirir (Abramowitz, Whiteside, Kalsy ve Tolin, 2003; Fehm ve Hoyer, 2004). Aslında bireylerin bu tip stratejiler geliştirmeleri düşüncelerinden kurtulmak için izledikleri doğal bir çabadır fakat bu çabanın sonuçları bazen başarısız olabilir ve birey bu yüzden düşüncelerini daha fazla kontrol etme çabası içine girebilir (Yorulmaz, Baştuğ, Tüzer ve Göka, 2013). Örneğin OKB hastalarının diğerlerine göre düşüncelerini daha çok kontrol etme çabası içine girdiklerini ve düşüncelerini bastırmaya çalıştıkça obsesyonun sıklığının daha da arttığı iddia edilmiştir (Janeck ve Calamari, 1999; Magee, Harden ve Teachman, 2012; Najmi ve Wegner, 2008; Purdon, 1999; Purdon ve Clark, 1999; Tolin, Abramowitz, Hamlin, Foa ve Synodi, 2002; Yorulmaz ve diğerleri, 2013). Aynı durum travma sonrası stres bozukluğu yaşayan bireyler için de geçerlidir (Aikins ve diğerleri, 2009). Bireyin bu amaçlar için kullandıkları stratejiler diğerlerinden daha uyumlu gözükmektedir (Abramowitz, 
Tolin ve Street, 2001). Wells ve Davies (1994) dikkat dağıtma, endişelenme, sosyal kontrol, yeniden değerlendirme ve kendine kızma şeklinde beş farklı düşünce kontrol stratejisinden bahsetmiş̧ir. Bireyin bu stratejileri kullanması içinde bulunduğu ruh haline ve ortama göre değişiklik gösterebilmektedir (Clark, 2005; Ekin-Eremsoy ve Inozu, 2015; Yorulmaz, 2016). Fakat unutulmamalıdır ki uyumluymuş gibi görünen bu zihinsel kontrol çabaları çoğunlukla olumsuz sonuçlar ortaya çıkarabilmektedir (Wegner ve Zanakos, 1994).

Yaygın kaygı bozukluğu, ruminasyon ve $\mathrm{OKB}$ gibi düşünce kontrolünün önemli olduğu psikolojik problemlerde ve bunlarla ilişkili patolojik sorunlarda (Coles ve Heimberg, 2005; Holeva, Tarrier ve Wells 2001; Meiser-Stedman ve diğerleri, 2014; Papageorgiou ve Wells 2003; Watkins ve Moulds, 2009; Wilson ve Hall, 2012) düşünce kontrol yeteneğinin değerlendirilmesi problemlerin çözümüne katkı sağlayacaktır (Wells, 2009). Düşünce kontrol yeteneği olmadığı ya da zayıf olduğu durumlarda stres, anskiyete, depresyon, kişilik bozuklukları, obsesif/kompulsif bozukluk kaçınılmazdır (Amiri Pichakolaei ve diğerleri, 2014; Luciano, Algarabel, Tomás ve Martínez, 2005; Williams ve diğerleri., 2010). Bu nedenle Düşünce Kontrol Yeteneği Ölçeğinin (DKYÖ) uyarlanması ulusal alanyazında hem torik hem de deneysel çalışmalara 1şık tutacaktır.

Daha önce ulusal alanyazında Yorulmaz ve Gençöz (2008) tarafından Türkçeye uyarlanan Düşünceleri Kontrol Etme Ölçeği bulunmaktadır. Fakat bu ölçek, hoşa gitmeyen ve istenmeyen düşüncelerle mücadele etmede kullanılan çeşitli uygulamaların sıklı̆ğnı değerlendirmek amacıyla kullanılmaktadır. Öte taraftan Düşünce Kontrol Yeteneği Ölçeği olumsuz düşüncelerle bir baş etme stratejisi değil olumlu/olumsuz düşünceleri kontrol edebilme yeteneğini genel manada değerlendirmek için kullanılan bir ölçme aracıdır. Ayrıca düşünce kontrol yeteneğini değerlendirebilecek bilişsel ve pozitif psikoloji bağlamında Türkiye'de benzer ölçek bulunmadığından böyle bir ölçek ulusal alanyazına katkı sağlayacaktır. Bu araştırmanın amacı, Luciano ve diğerleri. (2005) tarafından geliştirilen Düşünce Kontrol Yeteneği Ölçeğinin Türk kültürüne uyarlanması ve ölçeğin psikometrik özelliklerini incelemesidir.

\section{Yöntem}

\section{Birinci çalışma}

\section{Çalışma grubu}

Bu araştırma, iki farklı örneklem ile yürütülmüştür. İlk örneklem, Ağrı ilinde 204 (112 kadın, 92 erkek) öğretmen adayı; ikinci grup Kütahya ilinde formasyon eğitimi alan farklı bölümlerde öğrenim gören 251 katılımcıdan oluşmaktadır. İkinci grubun 148'i kadın, 103'ü erkektir. Ayrıca katılımcıların 149'u İ̈BF, 102'si Fen Edebiyat Fakültesi, 39'u fen bilgisi öğretmenliği, 30'u rehberlik ve psikolojik danışmanlık öğretmenliği, 36's1 sınıf öğretmenliği, 49'u Türkçe öğretmenliği, 18'i Müzik öğretmenliği, 32'si ilköğretim matematik öğretmenliği bölümlerinde devam etmektedirler. Çalışmaya katılan toplam 455 katılımcının yaşları 18 ile 44 arasında değişmekte olup; grubun yaş ortalaması $26.38(\mathrm{Ss}=5.41)$ olarak hesaplanmıştır.

\section{Veri toplama araçları}

Düşünce Kontrol Yeteneği Ölçeği (DKYÖ): Luciano ve diğerleri. (2005) tarafindan düşünceleri kontrol yeteneğini değerlendirmek için geliştirilen DKYÖ'nün orijinali 25 maddeden oluşmakta olup, 5'li Likert tipi (5=Kesinlikle katılıyorum 4=Kat1lıyorum, 3=Kararsızım, 2=Katılmıyorum, 1=Kesinlikle katılmıyorum,) bir ölçme aracıdır. Ölçek geliştirme çalışması, yaşları 18-55 arasında değişen katılımcılar üzerinde yapılmış, açımlayıcı faktör analizi sonucu özdeğeri 1'in üstünde 5 faktör elde edilmiş fakat saçılım diyagramı ölçeğin tek faktörlü olmasına karar verilmiştir. Ölçeğin madde faktör yükleri .46 ile .76 arasında değişmektedir. Ölçüt geçerliği çalışmasında DKYÖ ile Durumluk Anksiyete Ölçeği, Beck Depresyon Ölçeği, Maudsley Obsesif Kompulsif Envanteri, Penn State Endişe Ölçeği arasında p <0.01 önem düzeyine 
sırasıyla $r=-.82,-.68,-.50,-.74$ negatif ilişkiler bulunmuştur. DKYÖ Cronbach alfa iç tutarlık güvenirlik değeri $\alpha=.92$ şeklinde hesaplanmış, ayrıca düzeltilmiş madde korelasyon katsayılarının .42 ile .71 arasında olduğu saptanmıştır.

Tekrarlayıcı Düşünme Ölçeği (TDÖ): McEvoy, Mahoney ve Moulds (2010) tarafindan hazırlanan 31 ölçeğin Türkçe Uyarlaması Gülüm ve Dağ (2012) tarafindan gerçekleştirilmiştir. Ölçeğin faktör analizi sonucu en fazla faktör yükü alan $(0.70$ ve üstü) on madde seçilmiştir. $\mathrm{Bu}$ maddelerin uzun formla ilişkisi incelenmiş ve $r=.85(\mathrm{p}<0.01)$ olarak hesaplanmıştır. TDÖ’nün iç tutarlılık katsayısı .94 olarak hesaplanmıştır. TDÖ'nün uzun formla olan korelasyonu da .85 olarak bulunmuştur. Bu çalışmada Cronbach alfa iç tutarlık güvenirlik sayısı $\alpha=.89$ olarak tespit edilmiştir.

Bilişsel Esneklik Envanteri (BEE): Dennis ve Vander Wal (2010) tarafından geliştirilen ve Gülüm ve Dağ (2012) tarafından Türkçeye uyarlanan ölçek, alternatifler" ve "kontrol" olmak üzere 2 boyut 20 maddeden oluşmakta ve yedili Likert tipindedir. Bireylerin zor durumlarda iken dengeli düşünceler becerisini ölçmek için geliştirilmiştir. "Alternatifler" boyutu 13 maddede ve "Kontrol" alt boyutu ise 7 maddeden oluşmaktadır. Ölçeğin bütünü için Cronbach alfa iç tutarlık katsayısı birinci uygulama için .90 ve ikinci uygulama için .91 olarak bulunmuştur. "Alternatifler" alt boyutu için birinci ve ikinci uygulamada iç tutarlık katsayısı .91 olarak bulunmuştur. "Kontrol" alt boyutu için ise ilk uygulamada iç tutarlık katsayısı .86 ve ikinci uygulamada .84 olarak bulunmuştur. Bu çalışmada Cronbach alfa iç tutarlık güvenirlik sayıs $\alpha=.84$ olarak tespit edilmiştir.

\section{İşlem}

Öncelikle Düşünce Kontrol Yeteneği Ölçeğinin uyarlama çalışması için ölçeği geliştirenlerden Juan V. Luciano ve ölçeğin İngilizcesinden sorumlu Alishia D. Williams ile elektronik posta yoluyla iletişim geçilmiş ve gerekli izin alınmıştır. Türkçeye çevrilme süreci birkaç aşamalardan oluşmaktadır. Öncelikle ölçek Google'un çeviri sitesi yardımıyla İspanyolca'dan Türkçe'ye çevrilmiş, İspanyolca ve Türkçe bilen 1 dil uzmanına gösterilmiş fakat sağlıklı sonuç alınamadığ 1 için ölçeğin İngilizce versiyonundan çalışmalara devam etme kararı alınmıştır. İngiliz Dili Edebiyatı ve Amerikan Dili Edebiyatı mezunu 2 dil uzmanı tarafindan Türkçeye tercüme edilmiş, sonrasında ise bu Türkçe formlar tekrar İngilizceye çevrilmiştir. Dil uzmanlarından elde edinilen Türkçe form üzerinde anlam ve dil yapısı açısından gerekli düzeltmeler yapılmıştır. İngiliz dili ve edebiyatından 61 öğrenciyle dilsel eşdeğerlik çalışması yürütülmüştür. Ölçeğin son hali biri psikometride uzman olan 2'si psikolojik danışma ve rehberlik, 1 eğitim programları alanı olmak üzere 3 öğretim üyesine inceletilerek görüşleri doğrultusunda denemelik Türkçe form oluşturulmuştur. Uyum geçerliği için Tekrarlayıc1 Düşünme Ölçeği ve Bilişsel Esneklik Envanteri uygulama formuna eklenmiştir. Bu form çoğaltılarak katılımcılara uygulanmışır. Uygulama sonucu elde edilen veriler, bilgisayar ortamına aktarılmıştır. Ölçeğin maddelerine sırasıyla açıklayıcı faktör analizi (AFA) sonra da doğrulayıcı faktör analizi (DFA) yapılmıştır. Uyum indeks değerleri olarak genel kabul edilen AGFI, CFI, GFI, IFI, NFI, RFI için> .90, RMSEA ve SRMR için <.05 ölçüt olarak alınmıştır (Brown, 2006; Kline, 2005). Ölçüt geçerliği çalışması için toplam puan ortalamaları üzerinden Pearson momentler korelasyon analizi uygulanmış korelasyon katsayısını tespit edilmiştir. Verilerin analizi için istatistik paket programları kullanılmıştır.

\section{Bulgular}

\section{Dilsel eşdeğerlik}

DKYÖ'nün hem İngilizce hem Türkçesinin aynı gruba uygulanması sonucu her bir madde ve toplam puan için ilişkili örneklemler $t$ testi yapılmış olup sonuçlar Tablo 1'de gösterilmiştir. 
Tablo 1.

Dilsel Eşdeğerlik İçin İlişkili Örneklem T Testi Sonuçları

\begin{tabular}{|c|c|c|c|c|c|c|c|c|c|c|c|c|c|c|c|}
\hline No & Dil & $\bar{X}$ & $\mathrm{~N}$ & SS & $r$ & $\mathrm{t}$ & $\mathrm{p}$ & No & Dil & $\bar{X}$ & $\mathrm{~N}$ & SS & $\mathrm{r}$ & $\mathrm{t}$ & $\mathrm{p}$ \\
\hline \multirow{2}{*}{ M1 } & İngilizce & 2.80 & 61 & .60 & \multirow{2}{*}{$.92^{* *}$} & \multirow{2}{*}{$-2.91 *$} & \multirow{2}{*}{.01} & \multirow{2}{*}{ M14 } & İngilizce & 2.57 & 61 & .96 & \multirow[t]{2}{*}{$.90 * *$} & \multirow[t]{2}{*}{-1.52} & \multirow[t]{2}{*}{.13} \\
\hline & Türkçe & 3.03 & 61 & 1.43 & & & & & Türkçe & 2.66 & 61 & .96 & & & \\
\hline \multirow{2}{*}{ M2 } & İngilizce & 2.93 & 61 & 1.44 & \multirow{2}{*}{$.94 * *$} & \multirow{2}{*}{-1.62} & \multirow{2}{*}{.11} & \multirow{2}{*}{ M15 } & İngilizce & 3.00 & 61 & 1.22 & \multirow[t]{2}{*}{$.88 * *$} & \multirow[t]{2}{*}{.44} & \multirow[t]{2}{*}{.66} \\
\hline & Türkçe & 3.03 & 61 & 1.33 & & & & & Türkçe & 2.97 & 61 & 1.12 & & & \\
\hline \multirow{2}{*}{ M3 } & İngilizce & 3.41 & 61 & 1.28 & \multirow{2}{*}{$.97 * *$} & \multirow{2}{*}{-.44} & \multirow{2}{*}{.66} & \multirow{2}{*}{ M16 } & İngilizce & 3.41 & 61 & 1.38 & \multirow[t]{2}{*}{$.95 * *$} & \multirow[t]{2}{*}{-1.52} & \multirow[t]{2}{*}{.13} \\
\hline & Türkçe & 3.43 & 61 & 1.22 & & & & & Türkçe & 3.49 & 61 & 1.31 & & & \\
\hline \multirow{2}{*}{ M4 } & İngilizce & 3.10 & 61 & 1.34 & \multirow{2}{*}{$.90 * *$} & \multirow{2}{*}{-.65} & \multirow{2}{*}{.52} & M17 & İngilizce & 3.30 & 61 & 1.09 & $.92 * *$ & .30 & .77 \\
\hline & Türkçe & 3.15 & 61 & 1.24 & & & & 1017 & Türkçe & 3.28 & 61 & 1.07 & & & \\
\hline M5 & İngilizce & 3.36 & 61 & 1.05 & & & & & İngilizce & 2.82 & 61 & 1.23 & $.95 * *$ & -1.27 & .21 \\
\hline IMS & Türkçe & 3.33 & 61 & 1.01 & & & -. & 11 & Türkçe & 2.89 & 61 & 1.17 & & & \\
\hline M6 & İngilizce & 3.66 & 61 & 1.12 & & 1. & 3 & 1 & İngilizce & 3.61 & 61 & 1.08 & $.96 * *$ & .00 & 1 \\
\hline $1 \mathrm{MO}$ & Türkçe & 3.62 & 61 & 1.08 & & 1.1 & .3 & 11 & Türkçe & 3.61 & 61 & 1.02 & & & \\
\hline & İngilizce & 3.02 & 61 & 1.44 & & & & & İngilizce & 2.72 & 61 & 1.21 & $.89 * *$ & -1.15 & .25 \\
\hline M7 & Türkçe & 3.15 & 61 & 1.36 & & & 0 & 120 & Türkçe & 2.80 & 61 & 1.17 & & & \\
\hline M8 & İngilizce & 2.64 & 61 & 1.34 & & 44 & 66 & 121 & İngilizce & 3.74 & 61 & 1.05 & $.92 * *$ & .63 & .53 \\
\hline 108 & Türkçe & 2.62 & 61 & 1.27 & & .44 & 50 & $\sqrt{1}<1$ & Türkçe & 3.70 & 61 & 1.01 & & & \\
\hline M9 & İngilizce & 2.79 & 61 & 1.25 & & 33 & 74 & 122 & İngilizce & 3.57 & 61 & 1.12 & $.89 * *$ & .50 & .62 \\
\hline & Türkçe & 2.80 & 61 & 1.18 & $.93^{* * *}$ & 33 & 14 & 122 & Türkçe & 3.54 & 61 & .98 & & & \\
\hline & İngilizce & 2.90 & 61 & 1.27 & & 00 & 1 & & İngilizce & 3.18 & 61 & 1.12 & $.97 * *$ & .00 & 1 \\
\hline 110 & Türkçe & 2.90 & 61 & 1.22 & & .00 & 1 & 123 & & 3.18 & 61 & 1.13 & & & \\
\hline 1 & İngilizce & 2.84 & 61 & 1.10 & & 30 & & & İngilizce & 2.70 & 61 & 1.13 & $.91 * *$ & -1.62 & .11 \\
\hline 10111 & Türkçe & 2.82 & 61 & 1.07 & & .50 & & 10124 & Türkçe & 2.80 & 61 & 1.09 & & & \\
\hline M12 & İngilizce & 3.30 & 61 & 1.15 & & 9 & 37 & 425 & İngilizce & 3.25 & 61 & 1.30 & $.92 * *$ & -1.00 & .32 \\
\hline 1012 & Türkçe & 3.34 & 61 & 1.01 & & & .31 & $19 \angle 5$ & Türkçe & 3.31 & 61 & 1.26 & & & \\
\hline M13 & İngilizce & 2.90 & 61 & 1.21 & $93 *$ & -57 & 57 & & İngilizce & 77.51 & 61 & 3.71 & $.65 *$ & -1.71 & .09 \\
\hline M13 & Türkçe & 2.93 & 61 & 1.12 & 93 & .5 & .57 & Toplam & Türkçe & 78.39 & 61 & 5.27 & & & \\
\hline
\end{tabular}

$* * \mathrm{p}<.01, * \mathrm{p}<.05$

Tablo 1'de görüldüğü üzere tüm maddelerin İngilizce ve Türkçeleri arasında $p<.01$ önem düzeyinde istatistiksel olarak yüksek düzeyde korelasyon vardır. Ayrıca her bir maddenin İngilizce ve Türkçelerine ait puan ortalamaları karşılaştıııldığında $\mathrm{p}<.01$ önem düzeyinde istatistiksel olarak anlamlı bir farklılık yoktur. Genel olarak maddelerin dilsel eşdeğerliğin sağlandığı söylenebilir.

\section{Yapı geçerliğgi}

\section{Açıklayıcı faktör analizi (AFA)}

Ağrı ilindeki 204 katılımcıdan elde edilen veriler, ölçeğin yapı geçerliği çalışması için kullanılmış ve ölçeğin faktör yapısı incelenmiştir. Maddeler arasında korelasyonların olup olmadığına bakmak için korelasyon matrisi incelenmiş ve AFA'nın yapılabilmesine uygunluk gösterir nitelikte manidar ilişkilerin olduğu tespit edilmiştir. Sonrasında ise örneklem uygunluğu (Sampling adequacy) ve Barlett Sphericity testleri gerçekleştirilmiştir. Verilerin faktör analizine uygunluğu için KMO .60'dan yüksek ve Barlett testinin anlamlı çıkması gerekmektedir (Cerny ve Kaiser, 1977; Hadi, Abdullah ve Sentosa, 2016). Bu çalışmada KMO örneklem uygunluk katsayıs1 .89, Barlett Sphericity testi $\chi_{2}$ değeri ise $3183.82 \quad(\mathrm{sd}=300)(\mathrm{p}<.001)$ olarak bulunmuştur. Yapılan ilk açıklayıcı faktör analizinde, döngüsüz metot kullanılarak, saçılım diyagramı faktör çözümlemesiyle maksimum faktör sayısı incelenmiştir. 


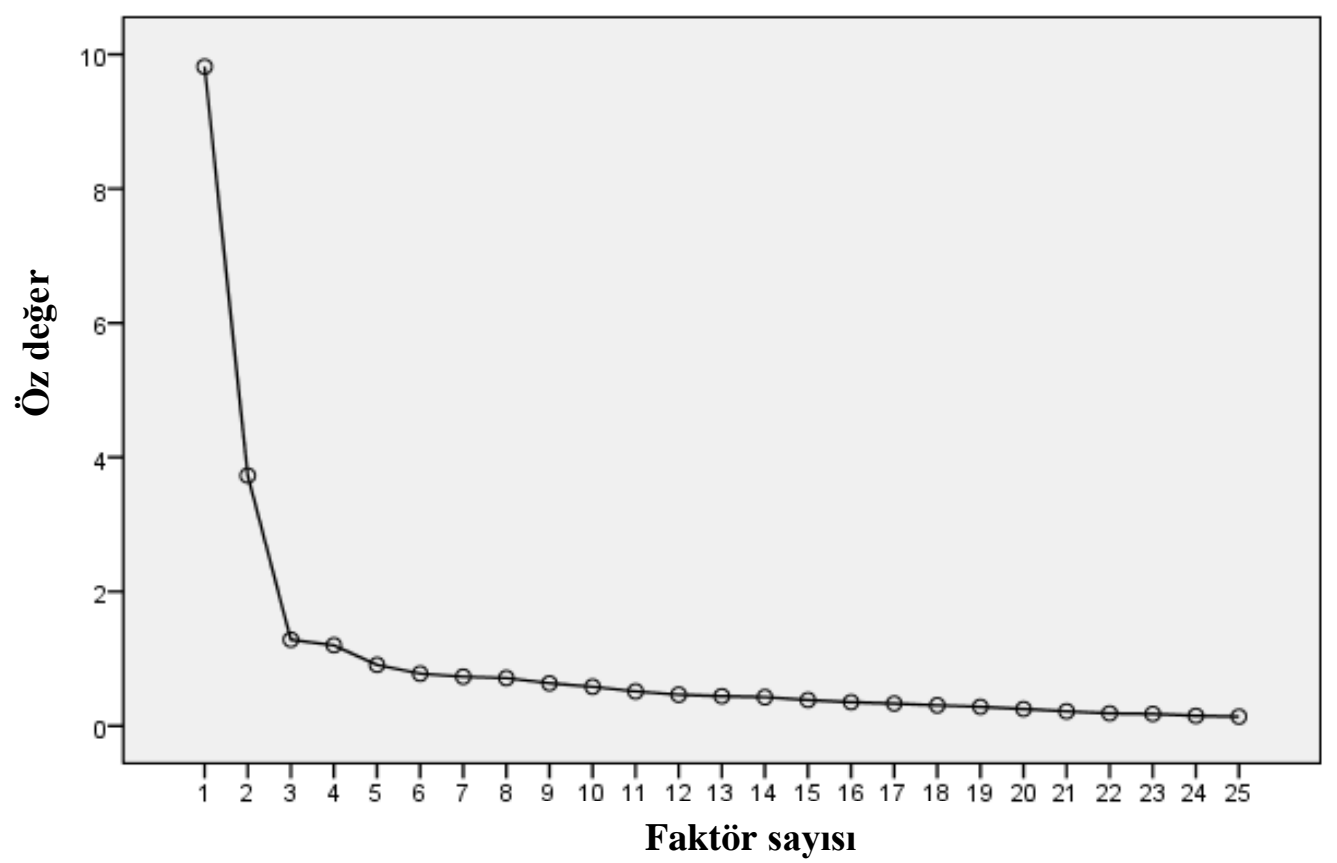

Şekil 1. Yamaç Grafiğgi

Şekil 1'deki yamaç grafiğinde görüldüğü üzere 25 maddenin orijinal halindeki gibi tek faktörde olmadığ 1 anlaşılmaktadır. Hatta 2 faktörlü ve 4 faktörlü yapılar elde edilebilmektedir. Fakat yine de faktör yüklerine bakmanın daha manidar olacağı düşünülmekte olup Tablo 2'de gösterilmiştir.

Tablo 2.

İlk AFA Madde Faktör Yükleri

\begin{tabular}{cccccccccc}
\hline $\begin{array}{c}\text { Madde } \\
\text { no }\end{array}$ & 1.faktör & 2.faktör & 3.faktör & 4. faktör & Mo & 1.faktör & 2.faktör & 3.faktör & 4.faktör \\
\hline $\mathrm{m} 1$ & .656 & -.224 & -.289 & -.238 & $\mathrm{~m} 14$ & .529 & .543 & .223 & .157 \\
$\mathrm{~m} 2$ & .722 & -.291 & -.267 & .143 & $\mathrm{~m} 15$ & .685 & -.326 & -.076 & .089 \\
$\mathrm{~m} 3$ & .696 & -.011 & .001 & .048 & $\mathrm{~m} 16$ & .495 & .609 & -.106 & .177 \\
$\mathrm{~m} 4$ & .474 & .604 & .121 & .312 & $\mathrm{~m} 17$ & .632 & -.424 & .285 & -.004 \\
$\mathrm{~m} 5$ & .690 & .166 & .053 & .050 & $\mathrm{~m} 18$ & .737 & -.132 & -.219 & -.136 \\
$\mathrm{~m} 6$ & .671 & -.400 & -.021 & .111 & $\mathrm{~m} 19$ & .660 & -.275 & .309 & -.278 \\
$\mathrm{~m} 7$ & .528 & .443 & -.141 & -.337 & $\mathrm{~m} 20$ & .599 & .455 & -.225 & .045 \\
$\mathrm{~m} 8$ & .691 & .173 & -.352 & .155 & $\mathrm{~m} 21$ & .663 & -.421 & .372 & -.038 \\
$\mathrm{~m} 9$ & .577 & .367 & .000 & -.159 & $\mathrm{~m} 22$ & .599 & -.285 & .459 & .283 \\
$\mathrm{~m} 10$ & .682 & -.268 & -.207 & .417 & $\mathrm{~m} 23$ & .682 & -.319 & .100 & -.192 \\
$\mathrm{~m} 11$ & .463 & .564 & .364 & -.394 & $\mathrm{~m} 24$ & .368 & .668 & .182 & .159 \\
$\mathrm{~m} 12$ & .755 & -.273 & .000 & .160 & $\mathrm{~m} 25$ & .518 & .382 & .003 & -.083 \\
$\mathrm{~m} 13$ & .704 & -.105 & -.237 & -.424 & Toplam & & & \\
& & & & & varyans & $(\%)$ & 14.76 & 4.95 & 4.79 \\
& & & & & $(\%)$ & $(\%)$ & $(\%)$ & $(\%)$ \\
\hline
\end{tabular}

Tablo 2'de görüldügü üzere bazı maddelerin diğer faktörlerin altında faktör yüklerinin .33 'den fazla olduğu tespit edilmiş̧ir. Örneğin 4., 6., 7., 8., 9., 10., 11., 13., 14., 15., 16., 17. , 
20., 21., 22., 24. maddeler birden fazla faktör altında yer almaktadır. Ayrıca Ho'ya (2014) göre madde faktör yük değeri .33 olarak kriter alınırsa o faktörün toplam varyansın en az \%10'unun açıklaması gerekmektedir (s.244). Bu bağlamda 3 ve 4. faktörler çıkarılırsa 2 faktörlü bir yap1 oluşmaktadır. Yamaç grafiğini göre 4 faktörlü, madde faktör yük değerlerine göre 2 faktörlü bir yapıyla uğraşmak yerine ölçeğin orijinal formuna uygun olarak tek faktörle sınırlandırılması gerektiği kanısına ulaşılmış ve temel bileşenler tekniği ile oblik döndürme faktör çözümlemesi sonuçları tek faktörle sınırlandırılarak tekrar AFA yapılmıştır. Yapılan analiz sonucunda toplam varyansın \%42.49'unu açıklayan, 25 maddeden oluşan ve özdeğeri 1.00'in üzerinde olan tek faktörlü bir yapı elde edilmiş ve sonuçlar Tablo 3 'te gösterilmiştir. Aynı problemler ölçeğin orijinal versiyonuna ait analizlerde de karşılaşıldığı için yazarlar tek faktörle sınırlandırmıştır.

Tablo 3.

AFA Faktör Yükleri ve Varyans Değeri

\begin{tabular}{cccc}
\hline $\begin{array}{c}\text { Madde } \\
\text { no }\end{array}$ & Faktör yükü & Madde no & Faktör yükü \\
\hline $\mathrm{m} 1$ & .656 & $\mathrm{~m} 14$ & .529 \\
$\mathrm{~m} 2$ & .722 & $\mathrm{~m} 15$ & .685 \\
$\mathrm{~m} 3$ & .696 & $\mathrm{~m} 16$ & .495 \\
$\mathrm{~m} 4$ & .474 & $\mathrm{~m} 17$ & .632 \\
$\mathrm{~m} 5$ & .690 & $\mathrm{~m} 18$ & .737 \\
$\mathrm{~m} 6$ & .671 & $\mathrm{~m} 19$ & .660 \\
$\mathrm{~m} 7$ & .528 & $\mathrm{~m} 20$ & .599 \\
$\mathrm{~m} 8$ & .691 & $\mathrm{~m} 21$ & .663 \\
$\mathrm{~m} 9$ & .577 & $\mathrm{~m} 22$ & .599 \\
$\mathrm{~m} 10$ & .682 & $\mathrm{~m} 23$ & .682 \\
$\mathrm{~m} 11$ & .463 & $\mathrm{~m} 24$ & .368 \\
$\mathrm{~m} 12$ & .755 & $\mathrm{~m} 25$ & .518 \\
$\mathrm{~m} 13$ & .704 & Toplam varyans & 42.49 \\
& \multicolumn{3}{c}{} \\
\hline
\end{tabular}

Tablo 3'te görüldüğü üzere maddelerin faktör yükleri .37 ile .75 arasında sıralanmaktadır. Elde edilen bulgulara göre ölçeğin madde faktör yapısının Türk kültürüne uygun olduğu ancak maddelerin doğrulanması gerektiği sonucuna ulaşılmıştır.

\section{Doğrulayıcı faktör analizi}

Ölçek ifadelerinin Türk kültüründe doğrulanıp doğrulanmadığını saptamak için Kütahya'dan 255 formasyon öğrencisinden elde edilen verilere tek boyutlu model için uygulanan doğrulayıc1 faktör analizinde uyum indeksi değerleri: $\chi^{2}=221.42$, $\mathrm{sd}=76\left(\chi^{2} / \mathrm{sd}=2.91\right)$, RMSEA $=.066$, CFI $=$ $.92, \mathrm{IFI}=.93, \mathrm{NFI}=.93, \mathrm{RFI}=.94, \mathrm{GFI}=.93, \mathrm{SRMR}=.042$ olarak bulunmuş olup sonuçlar Şekil 2 'de verilmiştir. 


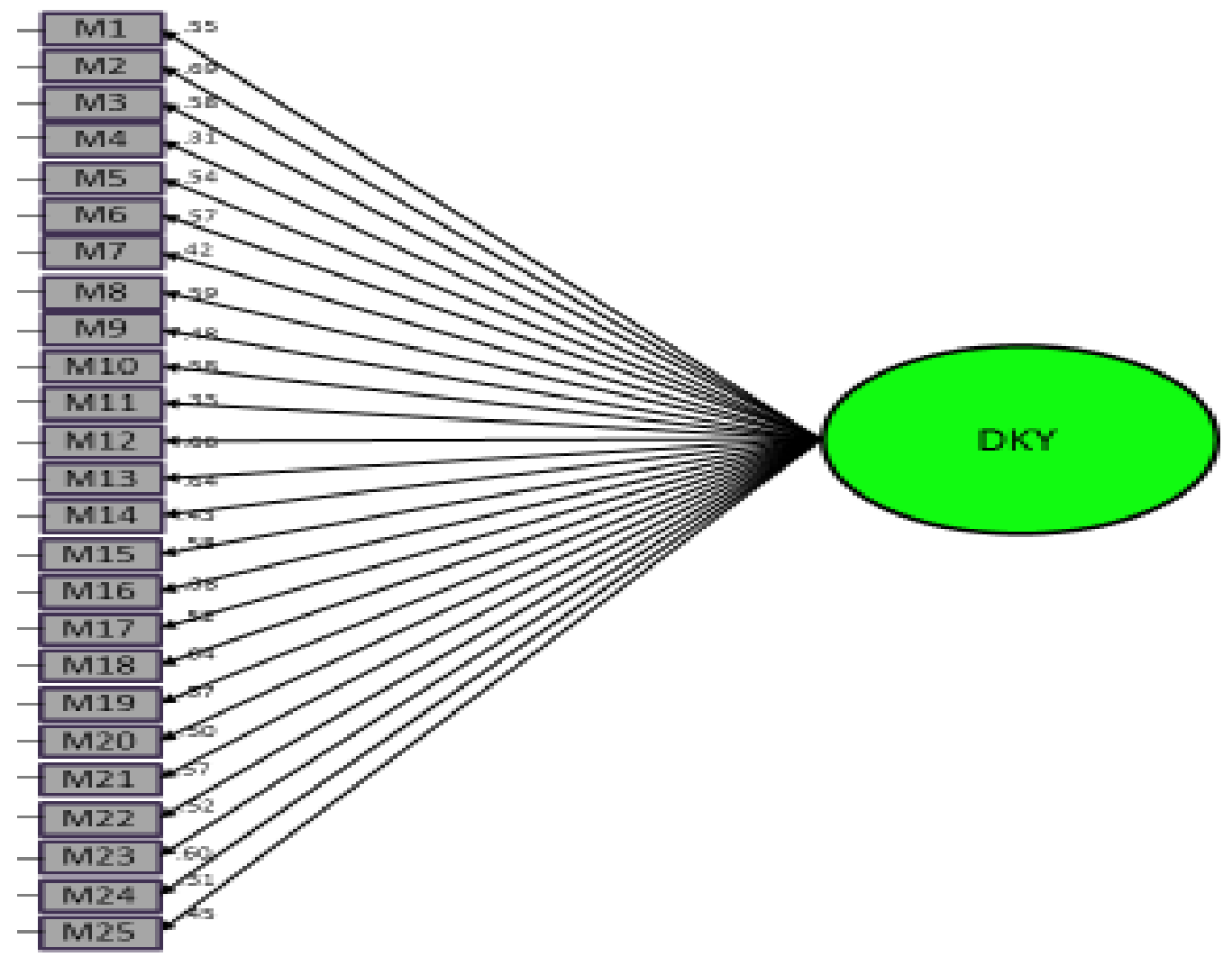

Şekil 2. DKYÖ-25 DFA Diyagramı

Şekil 2’de görüldüğü üzere ölçeğin DFA faktör yükleri .31 ile .69 ( $\lambda, \mathrm{p}<.01)$ arasında siralanmaktadır.

\section{Uyum geçerliği}

Uyum geçerliği çalışmasında DKYÖ ile Tekrarlayıcı Düşünme Ölçeği arasında $p<.01$ önem düzeyinde $r=-.62$, DKYÖ ile Bilişsel esneklik (alternatifler) ve Bilişsel esneklik (kontrol) arasında $\mathrm{p}<.01$ önem düzeyinde sırasıyla $r=.53 ; .65$ pozitif ilişkiler bulunmuştur.

\section{Güvenirlik}

Cronbach alfa iç tutarlık güvenirlik katsayısı $\alpha=.93$ olarak bulunmuştur.

\section{Madde analizi}

Düzeltilmiş madde-toplam korelasyonu. Yapılan analiz sonucunda ölçeğin düzeltilmiş maddetoplam korelasyon katsayıları .37 ile .70 arasında siralanmakta olup sonuçlar Tablo 4'te verilmiştir.

Tablo 4.

DKYÖ Düzeltilmiş Madde-Toplam Korelasyon Değerleri

\begin{tabular}{lccc}
\hline Madde no & $\begin{array}{c}\text { Düzeltilmiş madde toplam } \\
\text { korelasyon katsayıs1 }\end{array}$ & Madde no & $\begin{array}{c}\text { Düzeltilmiş madde toplam } \\
\text { korelasyon katsayıs }\end{array}$ \\
\hline $\mathrm{m} 1$ & .594 & $\mathrm{~m} 14$ & .525 \\
$\mathrm{~m} 2$ & .659 & $\mathrm{~m} 15$ & .620 \\
$\mathrm{~m} 3$ & .654 & $\mathrm{~m} 16$ & .490 \\
$\mathrm{~m} 4$ & $\mathrm{~m} 17$ & .567 \\
$\mathrm{~m} 5$ & .469 & $\mathrm{~m} 18$ & .685 \\
\hline
\end{tabular}




\begin{tabular}{llll}
\hline $\mathrm{m} 6$ & .600 & $\mathrm{~m} 19$ & .603 \\
$\mathrm{~m} 7$ & .512 & $\mathrm{~m} 20$ & .585 \\
$\mathrm{~m} 8$ & .656 & $\mathrm{~m} 21$ & .594 \\
$\mathrm{~m} 9$ & .556 & $\mathrm{~m} 22$ & .541 \\
$\mathrm{~m} 10$ & .621 & $\mathrm{~m} 23$ & .619 \\
$\mathrm{~m} 11$ & $\mathrm{~m} 24$ & .369 \\
$\mathrm{~m} 12$ & .460 & $\mathrm{~m} 25$ & .499 \\
$\mathrm{~m} 13$ & .700 & & \\
\hline
\end{tabular}

Tablo 4'te görüldüğü üzere 24. madde hariç tüm maddelerin düzeltilmiş madde toplam korelasyon değerleri .40 ve üzerindedir.

\section{İkinci çalışma}

Birinci çalışmadaki 25 maddelik DKYÖ'nün AFA sonucunda maddelerin faktör yüklerinin .33'ten büyük olarak farklı faktörler altında yer alması, ayrıca diğer psikometrik özelliklerine ve 2 alan uzmanının da görüşüne dayanarak ölçeğin 8 maddelik halinin psikometrik özelliklerinin incelenmesi için ikinci bir çalışmanın yapılması amaçlanmıştır.

\section{Çalışma grubu}

İkinci çalışmada Kütahya ilinde 201 (133 kadın, 68 erkek) öğretmen adayından oluşmaktadır. Katılımcının yaşları 21 ile 24 arasında olup; yaş ortalaması 21.46 olarak hesaplanmıştır.

\section{Veri toplama araçları}

Düşünce Kontrol Yeteneği Ölçeği (DKYÖ): Luciano ve diğerleri. (2005) tarafından geliştirilen Sarıçam ve Çelik (2017) tarafından Türk kültürüne uyarlanan DKYÖ'nün orijinali 25 maddeden oluşmakta olup, 5'li Likert tipi (1=Kesinlikle katılmıyorum, 2=Katılmıyorum, 3=Kararsızım, 4=Katılıyorum, 5=Kesinlikle katılıyorum) bir ölçme aracıdır. DKYÖ'nün ilk psikometrik özellikleri yukarıdaki birinci çalışmada gösterilmiştir.

\section{İşlem}

Araştırmacının yürüttüğü lisans dersleri sonunda eğitim fakültesi son sınıf öğrencilerine bir ölçek uyarlama çalışması yapıldı ğı ve onların desteğine ihtiyacı olunduğu söylenmiş ve gönüllü öğrencilere ölçeğin 25 maddelik uzun versiyonu dağıtılmış, her öğrenci bir kod vererek form doldurulmuştur. İki hafta sonra aynı öğrencilere 8 maddelik kısa versiyonu verilmiş ve öğrenciler önceki kodlarıyla bu formları doldurmuştur. Elde edilen veriler bilgisayar ortamına aktarılmış ve uygun istatistiki çözümlemelerle psikometrik özellikleri incelenmiştir.

\section{Bulgular}

\section{Yapı Geçerliği}

İkinci çalışmada KMO örneklem uygunluk katsayısı .88, Barlett Sphericity testi $\chi_{2}$ değeri ise $698.23(\mathrm{sd}=28)(\mathrm{p}<.001)$ olarak bulunmuştur. Serbest bırakılarak manipüle edilmeden yapılan AFA sonucu Tablo 5'te verilmiştir. 
Tablo 5.

AFA Faktör Yükleri

\begin{tabular}{cc}
\hline Madde no & Faktör yük \\
\hline $\mathrm{m} 1$ & .74 \\
$\mathrm{~m} 2$ & .79 \\
$\mathrm{~m} 3$ & .71 \\
$\mathrm{~m} 5$ & .65 \\
$\mathrm{~m} 12$ & .79 \\
$\mathrm{~m} 18$ & .76 \\
$\mathrm{~m} 19$ & .73 \\
$\mathrm{~m} 23$ & .75 \\
Toplam varyans $(\%)$ & 55 \\
\hline
\end{tabular}

Tablo 5'te görüldüğü üzere faktör yük değerleri .65 üzerinde olup 8 maddelik tek faktörlü model toplam varyansın \%55'nin açılamaktadır.

Sekiz maddelik yapının doğrulayıcı faktör analizinde uyum indeksleri: $\chi^{2}=39.61$, sd $=20$ $\left(\chi^{2} / \mathrm{sd}=1.98\right), \mathrm{CFI}=.97, \mathrm{GFI}=.93, \mathrm{IFI}=.97, \mathrm{NFI}=.95, \mathrm{RFI}=.93, \mathrm{SRMR}=.048$ olarak çı1kmış, sonuçlar Şekil 3'te gösterilmiştir.

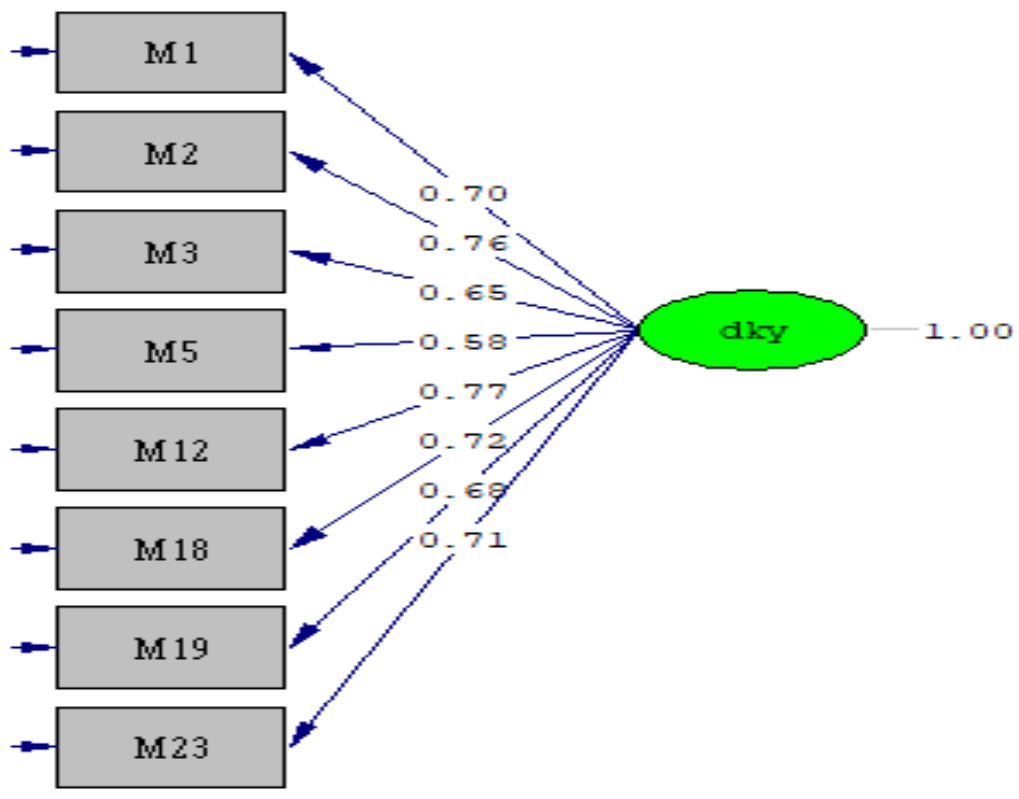

Şekil 3. DKYÖ-8 DFA Diyagramı

Şekil 3’te görüldüğü üzere ölçeğin DFA faktör yükleri .58 ile .77 arasında sıralanmaktadır.

\section{Uyum geçerliği}

Ölçüt geçerliği çalışmasında DKYÖ-8 ile DKYÖ-25 arasında $\mathrm{p}<.01$ önem düzeyinde $r=.85$, pozitif ilişki bulunmuştur.

\section{Güvenirlik}

Cronbach alfa iç tutarlık güvenirlik katsayısı $\alpha=.88$ olarak bulunmuştur. 


\section{Madde analizi}

Düzeltilmiş madde-toplam korelasyoni. Yapılan analiz sonucunda ölçeğin düzeltilmiş maddetoplam korelasyon katsayıları .56 ile .71 arasında sıralanmakta olup sonuçlar Tablo 6'da verilmiştir.

Tablo 6.

DKYÖ-8 Düzeltilmiş Madde-Toplam Korelasyon Değerleri

\begin{tabular}{lc}
\hline Madde no & $\begin{array}{c}\text { Düzeltilmiş madde toplam } \\
\text { Korelasyon katsayis1 }\end{array}$ \\
\hline $\mathrm{m} 1$ & .64 \\
$\mathrm{~m} 2$ & .71 \\
$\mathrm{~m} 3$ & .61 \\
$\mathrm{~m} 4$ & .56 \\
$\mathrm{~m} 5$ & .70 \\
$\mathrm{~m} 6$ & .67 \\
$\mathrm{~m} 7$ & .64 \\
$\mathrm{~m} 8$ & .66 \\
\hline
\end{tabular}

Tablo 6'da görüldüğü üzere tüm maddelerin düzeltilmiş madde toplam korelasyon değerleri .50 ve üzerindedir.

\section{Tartışma, Sonuç ve Öneriler}

$\mathrm{Bu}$ çalışmada yetişkinlerin düşünce kontrol yeteneklerini değerlendirmeye yönelik DKYÖ'nin 25 maddelik versiyonunun Türkçeye uyarlanması ve 8 maddelik kısa formunun psikometrik özelliklerinin incelenmesi amaçlanmıştır. Bu amaç doğrultusunda DKYÖ’nin geçerliği, yap1 geçerliği ve uyum geçerliliği ile belirlenmiştir. Faktör analizi, doğrulayıcı faktör analizi (DFA) ve açıklayıcı faktör analizi (AFA) şeklinde yapılmıştır. Açıklayıcı faktör analizi (AFA) uygulanmasının nedeni Düşünce Kontrol Yeteneği Ölçeğinin orijinal formunun faktör yapısının Türk örnekleminde belirlemek, doğrulayıcı faktör analizi (DFA) kullanılmasının nedeni orijinal formun faktör yapısının yetişkinler üzerinde doğrulanıp doğrulanmadığını sınamaktı (Büyüköztürk, 2019; Uyumaz, Mor-Dirlik ve Çokluk, 2016). Açıklayıcı faktör analizi (AFA) sonucunda faktör yükleri literatürde kabul edilebilir değer olan .30' dan (Büyüköztürk, 2019) yüksektir. Doğrulayıcı faktör analizi (DFA) sonucu ise ölçeğin tek boyutlu olarak iyi uyum verdiği ve kabul edilebilir bir uyum değerine sahip olduğu söylenebilir. Çünkü SRMR ile RMSEA değerinin .05 ve altında çıkmas1 iyi uyum değerini, .08 ve altında olması ise kabul edilebilir bir uyum değerini göstermektedir. Ayrıca CFI, GFI, IFI, NFI, RFI değerlerinin .90 üstü çıkması normal uyumu, .95 üstü çıkması mükemmel uyumu göstermektedir (Byrne, 2009; Tabachnick ve Fidell, 2012). Uyum geçerliği çalışması sonucunda ise ölçeğin uzun ve kısa formları arasında anlamlı ve yüksek düzeyde ilişkili olduğu sonucuna ulaşılmıştır. Düşünce Kontrol Yeteneği Ölçeğinin güvenirlik çalışmaları sonuçları incelendiğinde ise madde toplam korelasyonu katsayıları, Cronbach-alfa iç tutarlık ile test-tekrar test yöntemiyle elde edilen korelasyon katsayılarının kabul edilebilir düzeyde olduğu tespit edilmiştir. Literatürde Cronbach-alfa iç tutarlık güvenirlik katsayısı minimum değeri .70; düzeltilmiş madde toplam korelasyon değerlerinin .30 kriterinden büyük olması (Büyüköztürk, 2019; Erkuş, 2016) Düşünce Kontrol Yeteneği Ölçeğinin psikolojik ölçme aracı geliştirme ve uyarlama kriterlerine uygun olduğunu göstermektedir.

Uyarlanan ölçek maddelerinin psikometrik özellikleri özgün formu ile karşılaştırılacak olursa: Uyum indeksi değerleri özgün ölçekten çok daha yüksek olup; iç tutarlık güvenirlik katsayısı daha yüksektir. Uyum geçerliği (ölçüt geçerliliği) çalışmasında özgün formun daha fazla değişkenle ilişkisine bakıldığı görülmüsstür. Ayrıca ölçeğin Türk örneklemi geçerlik ve 
güvenirlik değerleri William ve diğerleri. (2010) tarafından New South Wales Üniversitesi örneklemi ile yapılmış çalışmanın geçerlik ve güvenirlik değerlerinden daha iyidir. Öte taraftan ölçeğin 25 maddelik ve 8 maddelik sürümlerinin psikometrik değerleri karşılaştırıldığında 8 maddelik kısa formun geçerlik ve madde analizi değerleri daha iyi olup, iç tutarlık güvenirlik değeri daha düşüktür. Bir diğer ifadeyle ölçeğin kısa sürümünün düşünce kontrol yeteneğini değerlendirmede kullanılabileceği söylenebilir.

Sonuç olarak, Düşünce Kontrol Yeteneği Ölçeğinin uzun ve kısa formlarının geçerlik ve güvenirlik çalışmalarından elde edilen bulgular, Türk kültüründe yetişkinlerin düşünce kontrol yeteneğini geçerli ve güvenilir bir şekilde ölçmek amacıyla kullanılabileceğini göstermektedir. Bunun yanı sıra ölçeğin geçerlik ve güvenirliği ile ilgili olarak aşağıdaki öneriler ile çalışma genişletilebilir:

- DKYÖ-25 için AFA yapılırken tek boyutla sınırlandırma yapılmış, fakat faktör yapısı serbest bırakılarak oluşabilecek faktörler alanyazın değerlendirilerek isimlendirilebilir.

- Farklı ölçme araçları (Ruminasyon, Depresyon Anksiyete Stress Ölçeği gibi), kullanılarak ölçeğin ölçüm gücü arttırılabilir.

\section{Kaynaklar}

Abramowitz, J. S., Whiteside, S., Kalsy, S. A. ve Tolin, D. F. (2003). Thought control strategies in obsessive-compulsive disorder: A replication and extension. Behaviour Research \& Therapy, 41(5), 529-540. http://dx.doi.org/10.1016/S0005-7967(02)00026-8

Abramowitz, J. S., Tolin, D. F. ve Street, G. P. (2001). Paradoxical effects of thought suppression: A meta-analysis of controlled studies. Clinical Psychology Review, 21(5), 683-703. http://dx.doi.org/10.1016/S0272-7358(00)00057-X

Aikins, D. E., Johnson, D. C., Borelli, J. L., Klemanski, D. H., Morrissey, P. M. ve Tolin, D. F. (2009). Thought suppression failures in combat PTSD: A cognitive loadhypothesis. Behaviour Research and Therapy, 47(9), 744-751. http://dx.doi.org/10.1016/j.brat. 2009.06.006

Amiri Pichakolaei, A., Fahimi, S., Bakhshipour Roudsari, A., Fakhari, A., Akbari, E. ve Rahimkhanli, M. (2014). A comparative study of thought fusion beliefs and thought control strategies in patient with obsessive-compulsive disorder, major depressive disorder and normal people. Iranian Journal of Psychiatry and Behavioral Sciences, $8(3), 33-41$.

Başerer, D. (2017). Bir düşünme türü olarak mantıksal düşünme. The Journal of Academic Social Sciences, 5(41), 433-442.

Başerer, D. ve Duman, E. Z. (2018). Akademisyenlerin mantıksal düşünmeye ilişkin algıları. Journal of Higher Education \& Science, 8(1), 136-144. http://dx.doi.org/10.5961/jhes. 2018.256

Brewin, C. R. ve Beaton, A. (2002). Thought suppression, intelligence, and working memory capacity. Behaviour Research and Therapy, 40(8), 923-930. http://dx.doi.org/10.1016/ S0005-7967(01)00127-9

Brown, T. A. (2006). Confirmatory factor analysis for applied research. New York: The Guilford Press.

Byrne, B. M. (2009). Structural Equation Modeling with AMOS: Basic concepts, applications, and programming, second edition (Multivariate Applications Series). Routledge.

Büyüköztürk, Ş. (2019). Sosyal bilimler için veri analizi el kitabı istatistik, araştırma deseni SPSS uygulamalarl ve yorum. Ankara: Pegem A Yayınc1lık.

Cerny, B. A. ve Kaiser, H. F. (1977). A study of a measure of sampling adequacy for factoranalytic correlation matrices. Multivariate Behavioral Research, 12(1), 43-47. http://dx.doi.org/10.1207/s15327906mbr1201_3

Clark, D. A. (Ed.). (2005). Intrusive thoughts in clinical disorders: Theory, research, and treatment. New York, NY, US: Guilford Press. 
Coles, M. E. ve Heimberg, R. G. (2005). Thought Control strategies in generalized anxiety disorder. Cognitive Therapy and Research, 29(1), 47-56. http://dx.doi.org/10.1007 /s10608-005-1647-x

Dennis, J. P. ve Vander Wal, J. S. (2010). The cognitive flexibility inventory: Instrument development and estimates of reliability and validity. Cognitive Therapy and Research, 34(3), 241-253. http://dx.doi.org/10.1007/s10608-009-9276-4

Ekin-Eremsoy, C. ve Inozu, M. (2015). The role of magical thinking, religiosity and thoughtcontrol strategies in obsessive-compulsive symptoms in a Turkish adult sample. Behavior Change, 33(1), 1-14. http://dx.doi.org/10.1017/bec.2015.16

Erkuş, A. (2016). Psikolojide ölçme ve ölçek geliştirme-1. Temel kavramlar ve işlemler. Ankara: Pegem A Yayıncilik.

Fehm, L. ve Hoyer, J. (2004). Measuring thought control strategies: The Thought Control Questionnaire and a look beyond. Cognitive Therapy and Research, 28(1), 105-117. http://dx.doi.org/10.1023/B:COTR.0000016933.41653.dc

Flavell, J. H. (1979). Metacognition and cognitive monitoring: A new area of cognitivedevelopmental inquiry. American Psychologist, 34(10), 906-911. http://dx.doi.org/ 10.1037/0003-066X.34.10.906

Garner, R. ve Alexander, P. A. (1989). Metacognition: Answered and unanswered questions. Educational Psychologist, 24(2), 143-158. http://dx.doi.org/10.1207/s15326985 ep2402_2

Güneş, F. (2012). Öğrencilerin düşünme becerilerini geliştirme. Türklük Bilimi Araştırmaları Dergisi, 32, 127-146.

Gülüm, İ. V. ve Dağ, İ. (2012). Tekrarlayıcı Düşünme Ölçeği ve Bilişsel Esneklik Envanterinin Türkçeye uyarlanması, geçerliliği ve güvenilirliği. Anatolian Journal of Psychiatry, 13, 216-223.

Hadi, N. U., Abdullah, N. ve Sentosa, I. (2016). An easy approach to exploratory factor analysis: Marketing perspective. Journal of Educational and Social Research, 6, 215223. http://dx.doi.org/10.5901/jesr.2016.v6n1p215

Holeva, V., Tarrier, N. ve Wells, A. (2001). Prevalence and predictors of acute stress disorder and PTSD following road traffic accidents: Thought control strategies and social support. Behavior Therapy, 32(1), 65-83. http://dx.doi.org/10.1016/S00057894(01)80044-7

Janeck, A. S. ve Calamari, J. E. (1999). Thought suppression in obsessive-compulsive disorder. Cognitive Therapy and Research, 23(5), 497-509. http://dx.doi.org/10.1023 /A:101872040

Kaçar, M. ve Sarıçam, H. (2015). Sınıf öğretmen adaylarının üst biliş farkındalıkları ile matematik kayg1 düzeyleri üzerine bir çalışma. Trakya Üniversitesi Eğitim Fakültesi Dergisi, 5(2), 137-152.

Kline, R. B. (2005). Principles and practice of structural equation modeling (2 nd ed.). New York: The Guilford Press.

Luciano, J. V., Algarabel, S., Tomás, J. M. ve Martínez, J. L. (2005). Development and validation of the Thought Control Ability Questionnaire. Personality and Individual Differences, 38(5), 997-1008. http://dx.doi.org/10.1016/j.paid.2004.06.020

Magee, J. C., Harden, K. P. ve Teachman, B. A. (2012). Psychopathology and thought suppression: A quantitative review. Clinical Psychology Review, 32(3), 189-201. http://dx.doi.org/10.1016/j.cpr.2012.01.001

Martin, L. L. ve Tesser, A. (1996). Some ruminative thoughts. R. S. Wyer (Yay. haz.). Advances in Social Cognition, içinde (ss. 1-47). Mahwah, NJ: Lawrence Erlbaum.

McEvoy, P. M., Mahoney, A. E. J. ve Moulds, M. L. (2010). Are worry, rumination, and postevent processing one and the same? Development of the Repetitive Thinking Questionnaire. Journal of Anxiety Disorders, 24(5), 509-519. http://dx.doi.org/10.1016/ j.janxdis.2010.03.008 
Meiser-Stedman, R., Shepperd, A., Glucksman, E., Dalgleish, T., Yule, W. ve Smith, P. (2014). Thought control strategies and rumination in youth with acute stress disorder and posttraumatic stress disorder following single-event trauma. Journal of Child and Adolescent Psychopharmacology, 24(1), 47-51. http://dx.doi.org/10.1089/cap. 2013.0052

Najmi, S. ve Wegner, D. M. (2008). Thought suppression and psychopathology. A. J. Elliot (Yay. haz.). Handbook of approach and avoidance motivation, içinde (ss. 447-459). New York, NY, US: Psychology Press.

Papageorgiou, C. ve Wells, A. (2003). An empirical test of a clinical metacognitive model of rumination and depression. Cognitive Therapy and Research, 27(3), 261-273. http://dx.doi.org/10.1023/A:1023962332399

Presseisen, B. Z. (1991). Thinking skills: Meanings and models revisited. A. Costa, (Yay. haz.), Developing Minds: A Resource Book for Teaching Thinking. Revised Ed. Vol. 1, içinde (ss. 56-62). Alexandria, Virginia: Association for Supervision \& Curriculum Development.

Purdon, C. (1999). Thought suppression and psychopathology. Behavior Research and Therapy, 37(11), 1029-1054.

Purdon, C. ve Clark, D. A. (1999). Metacognition and obsessions. Clinical Psychology and Psychotherapy, 6(2), 102-110. http://dx.doi.org/10.1002/(SICI)1099-0879(199905) 6:2<102::AID-CPP191>3.0.CO;2-5

Reeve, R. A. ve Brown, A. L. (1985). Metacognition reconsidered: Implications for intervention research. Journal of Abnormal Child Psychology, 13(3), 343-356. http://dx.doi.org /10.1007/BF00912721

Sarıçam, H. (2018). Önleyici psikolojik danışma açısından koruyucu faktörler. F. Savi Çakar (Yay. haz.). Önleyici Psikolojik Danışma Kuram ve Uygulamaları, içinde (ss. 77-118). Ankara: PegemA Yayınları. http://dx.doi.org/10.14527/9786052413081

Sarıçam, H. ve Çelik, İ. (2018). Ergen ve Yetişkin Bilinçli Farkındalık Ölçeği (EYBFÖ) Türkçe formunun psikometrik özellikleri: Bir ön çalışma. D. Köksal ve A. Ataç (Yay. Haz.). VIII. Uluslararası Eğitimde Araştırmalar Kongresi Tam Metin Kitabı (ss.151-157). Manisa: Uluslararası Eğitim Araştırmacıları Derneği. http://dx.doi.org/10.13140 /RG.2.2.28382.33601

Tabachnick, B. G. ve Fidell, L. S. (2012). Using multivariate statsitics (6th ed.). Pearson.

Türk Dil Kurumu [TDK], (2019). 15 Mayıs 2019 tarihinde, Erişim adresi: http://tdk.gov.tr/index.php?option=com_gts\&arama=gts\&guid=TDK.GTS.5b7abf52c $994 \mathrm{e} 8.73903056$

Tolin, D. F., Abramowitz, J. S., Hamlin, C., Foa, E. B. ve Synodi, D. S. (2002). Attributions for thought suppression failure in obsessive-compulsive disorder. Cognitive Therapy and Research, 26(4), 505-517. http://dx.doi.org/10.1023/A:1016559117950

Tosun, A. ve Irak, M. (2008). Üst Biliş Ölçeği-30'un Türkçe uyarlaması, geçerliği, güvenirliği, kayg1 ve obsesif-kompülsif belirtilerle ilişkisi. Türk Psikiyatri Dergisi, 19(1), 67-80.

Uyumaz, G., Mor-Dirlik, E. ve Çokluk, Ö. (2016). Açımlayıcı faktör analizinde tekrar edilebilirlik: Kavram ve uygulama. Abant İzzet Baysal Üniversitesi Eğitim Fakültesi Dergisi, 16(2), 659-675.

Watkins, E. R. ve Moulds, M. L. (2009). Thought control strategies, thought suppression, and rumination in depression. International Journal of Cognitive Therapy, 2(3), 235-251. http://dx.doi.org/10.1521/ijct.2009.2.3.235

Wegner, D. M. ve Zanakos, S. (1994). Chronic thought suppression. Journal of Personality, 62(4), 615-640. http://dx.doi.org/10.1111/j.1467-6494.1994.tb00311.x

Wegner, D. M., Schneider, D. J., Carter, S. ve White, T. (1987). Paradoxical effects of thought suppression. Journal of Personality and Social Psychology, 53(1), 5-13.

Wells, A. (2009). Metacognitive therapy for anxiety and depression. New York: Guilford Press. 
Wells, A. ve Davies, M. I. (1994). The Thought Control Questionnaire: A measure of individual differences in the control of unwanted thoughts. Behaviour Research and Therapy, 32(8), 871-878. http://dx.doi.org/10.1016/0005-7967(94)90168-6

Williams, A. D., Moulds, M. L., Grisham, J. R., Gay, P., Lang, T., Kandris, E. ve Yap, C. (2010). A psychometric evaluation of the Thought Control Ability Questionnaire (TCAQ) and the prediction of cognitive control. Journal of Psychopathology and Behavioral Assessment, 32(3), 397-405. http://dx.doi.org/10.1007/s10862-009-9171-z

Wilson, C. ve Hall, M. (2012). Thought control strategies in adolescents: Links with OCD symptoms and meta-cognitive beliefs. Behavioral and Cognitive Psychotherapy, 40(4), 438-451. http://dx.doi.org/10.1017/S135246581200001X

Yorulmaz, O. (2016). Magical thinking and obsessional experiences: Mediator role of thought control strategies. TAF Preventive Medicine Bulletin, 15(4), 298-304. http://dx.doi.org/10.5455/pmb.1-1448977320

Yorulmaz, O. ve Gençöz, T. (2008). Obsessif-kompulsif bozukluk semptomların değerlendirilmesinde kullanılan İstem Dışı Düşünceleri Yorumlama Envanteri, Obsessif İnanışlar Ölçeği ve Düşünceleri Kontrol Etme Ölçeği'nin Türk örnekleminde incelenmesi. Türk Psikoloji Yazılarl, 11(22), 1-13.

Yorulmaz, O., Baştuğ, G., Tüzer, V. ve Göka, E. (2013). Obsesif-kompulsif bozukluğu olan hastalarda yanlış yorumlama, inançlar ve düşünce kontrol yöntemleri. Anadolu Psikiyatri Dergisi, 14, 183-191. http://dx.doi.org/10.5455/apd.36381

\section{Extended Abstract}

\section{Introduction}

The independent and original state of the mind that is apart from the sensation, perception, impression and designs, is defined as thinking (Turkish Language Association, [TDK], 2019). Thinking is a mental process, involving the logic of which individual has possession and which is realized through the knowledge and experiences (Başerer, 2017; Presseisen, 1991). Since thinking occurs naturally in the mind, most people avoid racking their brains by perceiving thinking as an ordinary simple situation and without giving thought to systematic thinking (Başerer \& Duman, 2018; Güneş, 2012). In this case, the concept of thought control manifests itself. Thought control ability (TCA) is a way of thinking through which individuals use to control unwanted and compelling / unexpected thoughts and whose control mechanism is controlled by the individual (Martin \& Tesser, 1996; Wells \& Davies, 1994). In brief, TCA is to try not to think about certain thoughts (Wells ve Davies, 1994). TCA without repression (thoughts), which is a precondition for Freud's defense mechanisms, eliminates destructive, harmful thoughts and enables to focus on creative activities. Suppression can also be automated after a while, but TCA is conscious. According to Wegner, Schneider, Carter and White (1987), the ability to control thought is a conscious, effortful process to stop compelling / intrusive thoughts. As a result of this process, access to cognitive resources should be provided. The second phase is the automatic monitoring process showing new examples of thought. The automatic monitoring process enables individual's mental recovery by activating the goaloriented thinking. In this context, the ability to control thought is within the capacity of selfregulation and it is the goal-oriented control of behaviors and thoughts. Advanced thought control is related to high working memory capacity and fluid intelligence (Brewin \& Beaton, 2002).

There is a Thought Control Ability Questionnaire adapted to Turkish by Yorulmaz and Gençöz (2008) and published in the national literature. However, this scale is used to evaluate the frequency of various methods which is used to cope with unwanted and unpleasant thoughts. Furthermore, the Thought Control Ability Questionnaire originally is not a strategy of coping with negative thoughts, but a measurement tool used to evaluate the ability to control positive / negative thoughts in general. Besides to this, this kind of scale will contribute to the national literature, since there is no similar scale which can evaluate thought control ability in the context 
of the cognitive and positive psychology in Turkey. In this study, it was aimed to adapt the Thought Control Ability Questionnaire developed by Luciano et al. (2005) to Turkish, and to examine the psychometric properties of the scale.

\section{Method}

\section{First study}

\section{The study group}

The study was conducted with two different study groups. The first group consists of 204 prospective teachers (112 females, 92 males) in A $\breve{g r}$ province; the second group consists of 251 participants who are studying at different departments and receiving formation training, in Kütahya province. Of the second group, 148 are females and 103 are males. In addition, 149 of the participants are studying at School of economics and administrative sciences, 102 are at Faculty of Arts and Sciences, 39 are at science teaching, 30 are at psychological counseling and guidance, 36 are at primary education teaching, 49 are at Turkish teaching, 18 are at music teaching, and 32 of them are studying at secondary school mathematics teaching departments. A total of 455 participants are between 18 and 44 years old, and the mean age was calculated as $26.38(\mathrm{SD}=5.41)$.

\section{Procedure}

First of all, it was contacted Juan V. Luciano who developed the scale and with Alishia D. Williams responsible for the English language of the scale via e-mail, and necessary permission was received for the adaptation study of the Thought Control Ability Questionnaire. The process of translating into Turkish consists of certain phases. Primarily, the scale was translated from Spanish to Turkish with the help of Google's translation site, and it was examined by a language specialist who knows Spanish and Turkish. But it was decided to continue the study with English version of the scale, since no healthy results could be obtained. The scale was translated into Turkish by two language experts graduated from English Language and American Language Literature and then these Turkish forms were translated into English again. Necessary corrections were made on the Turkish form edited by language experts in terms of meaning and language structure. The final version of the scale was examined by 3 faculty members, 1 of whom are experts in psychometrics, 2 of whom are experts in psychological counseling and guidance, and a tentative Turkish form was composed in the direction of their opinions. This form was applied to all participants by multiplied copies. After the data were computerized, firstly explanatory factor analysis (EFA) and then confirmatory factor analysis (CFA) were performed on items. Goodness of Fit index values were taken as $>.90$ for generally accepted AGFI, CFI, GFI, IFI, NFI, RFI, and as <.05 for RMSEA and SRMR (Brown, 2006; Kline, 2005). Pearson moments correlation analysis was applied to determine the correlation coefficient over the total score means in the criterion validity study. SPSS 17 and LISREL 8.54 programs were used for the analysis of the obtained data.

\section{Second Study}

Due to the fact that factor loadings of items obtained by EFA of TCAQ's 25 items were taken part under different factors as greater than .33 in the first study, and with the intention of examining the psychometric properties of the 8 -item version of the scale by depending on other psychometric properties and views of two expertise, it was aimed to make second study.

\section{The study group}

Participants in the second study consist of 201 (133 females and 68 males) teacher candidates who live in Kütahya province. The ages of the participants were between 21 and 24 years, and the mean age was calculated as 21.46 . 


\section{Procedure}

At the end of the undergraduate courses, researcher told to the students that a scale adaptation study was conducting to the senior students of the faculty of education and that he was needed their support. The 25-item long version of the scale was distributed to the volunteer students and a form was filled by giving each student a code. Two weeks later, the same students were given a short version of the 8-item version and the students filled these forms by using their previous codes. The data obtained were computerized and psychometric properties were examined by appropriate statistical analyzes.

\section{Discussion and Conclusion}

In this study, it was aimed to adapt the 25 -item version of the TCAQ into Turkish and to examine the psychometric properties of its 8-item short form in order to evaluate the thought control abilities of adults. In line with purpose, the validity of TCAQ was determined by factor analysis, concurrent validity. Factor analysis was conducted as explanatory factor analysis (EFA) and confirmatory factor analysis (CFA). The reason for the application of EFA was to determine the factor structure of the original form of the Thought Control Ability Questionnaire on the Turkish sample, and to test whether the factor structure of the original form was confirmed on adults (Büyüköztürk, 2019; Uyumaz, Mor-Dirlik \& Çokluk, 2016). As a result of the EFA, factor loadings are higher than .30 which is acceptable value in the literature (Büyüköztürk, 2019). As a result of the CFA, it can be said that the scale fits well in one dimension and has an acceptable goodness of fit value. Because, the fact that SRMR and RMSEA values are .05 and below, shows goodness of fit at high level, and that they are .08 and below shows acceptable goodness of fit. In addition, the fact that CFI, GFI, IFI, NFI, RFI values were above .90 indicates normal goodness of fit, and that were above .95 indicates perfect goodness of fit (Byrne, 2009; Tabachnick \& Fidell, 2012). As a result of fitness validity (criterion validity) study, it was concluded that the scale was valid. When the reliability studies of the Thought Control Ability Questionnaire were examined, it was seen that Cronbach-alpha internal consistency, item total correlation coefficients and correlation coefficients obtained by test-retest method were acceptable. In the literature, the fact that the minimum value of Cronbach-alpha internal consistency reliability coefficient was .70 and the fact that the corrected item total correlation values were greater than .30, shows that the Thought Control Ability Questionnaire meets the criteria of developing and adapting psychological measurement tools.

When the psychometric properties of the adapted scale are compared with its original form: The values of fit index are much higher than the original scale and the internal consistency reliability coefficient is higher as well. In the concurrent validity study, it was seen that the relationship of the original form between more variables was examined. In addition, validity and reliability values of the Turkish sample of the scale are better than the validity and reliability values of the study done by William et al (2010) using the sample of University of New South Wales. On the other hand, when the psychometric values of the 25-item and 8-item versions of the scale are compared, the validity and item analysis values of the 8-item short form are better, and its internal consistency reliability value is lower. In other words, it can be said that the short version of the scale can be used to evaluate the thought control ability.

As a result, the findings obtained from the validity and reliability studies of the long and short forms of the Thought Control Ability Questionnaire indicate that it can be used in a valid and reliable way to measure the thought control ability of adults living in in Turkish culture. Besides, the study can be extended in the context of the validity and reliability of the scale with the following recommendations:

- One-dimensional limitation was made when AFA was performed for TCAQ with 25 items. However, the factors that could occur by releasing the factor structure can be named after evaluating the literature.

- The measurement power of the scale can be increased by using different measuring tools (Rumination, Depression Anxiety Stress Scale). 